\title{
Kyrgyz Language
}

National Cancer Institute

\section{Source}

National Cancer Institute. Kyrgyz Language. NCI Thesaurus. Code C153980.

A T urkic language spoken in Kyrgyzstan, as well as China, Afghanistan, Kazakhstan,

Tajikistan, Turkey, Uzbekistan, Pakistan, and Russia. 